\title{
INVESTMENT BANKING, REPUTATION, AND THE UNDERPRICING OF INITIAL PUBLIC OFFERINGS*
}

\author{
Randolph P. BEATTY \\ University of Pennsylvania, Philadelphia, PA 19104, USA \\ Jay R. RITTER \\ University of Michigan, Ann Arbor, MI 48109, USA
}

Received August 1984, final version received June 1985

\begin{abstract}
This paper develops and tests two propositions. We demonstrate that there is a monotone relation between the (expected) underpricing of an initial public offering and the uncertainty of investors regarding its value. We also argue that the resulting underpricing equilibrium is enforced by investment bankers, who have reputation capital at stake. An investment banker who 'cheats' on this underpricing equilibrium will lose either potential investors (if it doesn't underprice enough) or issuers (if it underprices too much), and thus forfeit the value of its reputation capital. Empirical evidence supports our propositions.
\end{abstract}

\section{Introduction}

Ibbotson (1975) and Ritter (1984), among others, provide convincing evidence that initial public offerings are, on average, underpriced. In this paper, we argue that there is an equilibrium relation between the expected underpricing of an initial public offering and the ex ante uncertainty about its value. We also argue that this underpricing equilibrium is enforced by the investment banking industry. Furthermore, we present empirical evidence supporting our propositions.

Our results are crucially dependent upon the fact that, while many initial public offerings shoot up in price, many other issues decline in price once they start trading. Consequently, even though on average initial public offerings are underpriced, an investor submitting a purchase order car not be certain about an offering's value once it starts publicly trading. We call this uncertainty

\footnotetext{
${ }^{*}$ We wish to acknowledge useful discussions with Sanjai Bhagat, Harry DeAngelo, John Finnerty, Robert Heinkel, Kevin Rock and Robert Verrecchia, and with seminar participants at the University of Pennsylvania, Columbia, Berkeley, UCLA and the University of Rochester MERC Conference on Investment Banking and the Capital Acquisition Process. Detailed comments were also received from the editors of this journal, John Long and Cliff Smith. An earlier version of this paper was presented at the June 1984 Western Finance Association meetings. The data on initial public offerings have been generously made available by Howard and $\mathrm{Co}$.
} 
about the value per share 'ex ante uncertainty'. We argue that the greater is the ex ante uncertainty, the greater is the (expected) underpricing.

We also consider how this underpricing equilibrium is enforced. We argue that an issuing firm, which will go public only once, cannot make a credible commitment by itself that the offering price is below the expected market price once it starts trading. ${ }^{1}$ Instead, an issuing firm must hire an investment banker to take the firm public. ${ }^{2}$ An investment banker is in a position to enforce the underpricing equilibrium because it will be involved in many initial public offerings over time. We argue that any investment banker who 'cheats' on the underpricing equilibrium by persistently underpricing either by too little or by too much, will be penalized by the marketplace.

The structure of this paper is as follows. In section 2, we develop the relation between ex ante uncertainty and expected initial return. In section 3 , we address the issue of how this underpricing equilibrium is maintained. Section 4 describes the data used in our empirical tests. In section 5 , we present the empirical evidence and interpret our results. Section 6 consists of a summary and concluding remarks. We also include an appendix providing a formal model in which our underpricing result is demonstrated.

\section{The relation between ex ante uncertainty and expected initial return}

Numerous studies have found that, on average, initial public offerings are underpriced. Ritter (1984), for instance, reports that for the approximately 5000 firms that went public during 1960-82 in the U.S., the average initial public offering was trading at a price 18.8 percent higher than its offering price shortly after public trading started. ${ }^{3}$ The magnitude of this underpricing is

\footnotetext{
${ }^{1}$ The reason that a single issuing firm cannot, for example, post a bond to guarantee that there is a positive expected initial return, is that it is never observable. All that is observable is the realized initial return, which has two components - an expected initial return plus an 'error' term.

${ }^{2}$ There are other reasons for hiring an investment banker aside from our argument. Investment bankers have a comparative advantage at distributing securities, for example. Furthermore, given the public good nature of information, potential investors may demand that the issuing firm hire reputable certifiers of information, i.e., a public accounting firm and an investment banker, so that individual investors do not have to incur costs that are simultaneously being incurred by other potential investors. We do not address these other reasons.

${ }^{3}$ The 18.8 percent average price appreciation was computed using two slightly different methodologies. For 1960-76, the return period cver which this was measured is from the offering date to the end of the calendar month of offering, and this return is computed by subtracting the return on the market from the raw return over the period, which varies from 1 to 31 days in length. The data from 1960-70 are from Ibbotson and Jaffe (1975). For 1977-82, the return period is from the offering date to the first recorded closing bid price, which is usually on the same day as the offering. These 1977-82 returns are not adjusted for market movements. For the 1960-76 period, there are many missing observations (approximately 8 percent of all initial public offerings, usually smaller offerings, are omitted). For $1977-82$, there are no omissions. The differences in return calculations, and the difference in the missing observation rates, reflect the improved quality of price data from the over-the-counter market over time. For further discussion of the 18.8 percent figure, see Ritter (1984), pp. 216-218.
} 
substantially greater than that found for equity issues of firms that are already public, as documented by Smith (1977).

This persistent underpricing does not imply that an investor can expect to realize excess returns, however, due to institutional features of the market. The most salient feature of the initial public offering market is that, once the issuing firm and its managing underwriter (we use the terms underwriter and investment banker interchangeably) set an offering price, any excess demand for the issue creates a situation of quantity rationing, rather than further adjustment of the offering price. The majority of initial public offerings are subject to this quantity rationing. If this rationing was random across issues, it would merely mean that, for a given investor, the investment on which these high average initial returns was being earned was smaller than desired. The extent of rationing, however, is not random across issues. ${ }^{4}$

While on average initial public offerings have positive initial returns, a large fraction of them have price declines. The offerings that shoot up in price are much more commonly oversubscribed than those that decline in price. Consequently, an investor submitting purchase orders for all issues will find that one is allocated shares in the offerings that go up less frequently than in the offerings that decline in price. This creates a situation where the average initial return conditional upon receiving shares is lower than the average initial return conditional upon submitting a purchase order. In other words, an investor faces a 'winner's curse': if one is allocated the requested number of shares, one can expect that the initial return will be less than average.

If, on average, initial public offerings are underpriced, somebody must be realizing excess returns, even if a representative investor isn't. Since only some offerings go up in price, a potential investor has an incentive to incur costs doing security analysis to discern which issues are likely to appreciate in price. In equilibrium, the investors incurring these costs will earn sufficient profits to cover their costs. But this is what creates the winner's curse problem for the investors who are attempting to free ride. It is these free riders who are what we term representative investors. [In the appendix, following Rock $(1982,1986)$, we term investors who choose to incur information acquisition costs informed investors, and those who don't, uninformed investors. The uninformed investors are the free riders, the representative investors.]

Faced with this winner's curse problem, a representative investor will only submit purchase orders if, on average, initial public offerings are underpriced. The magnitude of the difference between the conditional returns, and thus the degree of underpricing, is directly related to the ex ante uncertainty about the value of an issue. This is because, as the ex ante uncertainty increases, the

\footnotetext{
${ }^{4}$ The extent of the rationing can be severe. The personal records of a major investor in initial public offerings which we were allowed to confidentially inspect disclosed that he was allocated less than 5 percent of the requested shares in many offerings.
} 
winner's curse problem intensifies. Roughly speaking, there is more to lose as ex ante uncertainty increases. Consequently, in order to be willing to submit a purchase order for shares in an offering with greater ex ante uncertainty, a representative investor will demand that more money be 'left on the table', in an expected value sense, via underpricing. This argument leads to our first proposition:

Proposition 1. The greater is the ex ante uncertainty about the value of an issue, the greater is the expected underpricing.

In the appendix, we formally prove Proposition 1 using Rock's $(1982,1986)$ model of the underpricing of initial public offerings.

It should be emphasized that the ex ante uncertainty which leads to the underpricing does not correspond to the CAPM concept of systematic risk. A representative investor who diversifies by submitting purchase orders for many initial public offerings in the face of the winner's curse problem merely guarantees that the realized average initial return will be less than the unconditional average initial return on the issues for which purchase orders were submitted.

\section{What mechanism enforces the underpricing equilibrium?}

In the previous section, we argued that the expected underpricing of an initial public offering increased as ex ante uncertainty increased. While this is an intuitively appealing result, a question concerning how this equilibrium is enforced naturally arises. Why doesn't an issuing firm 'cheat' and set too high an offering price? How is it that, on average, a representative investor is compensated for the winner's curse risk that one faces?

If investors were not able to somehow be assured that an issuing firm was leaving money on the table, in an expected value sense, the initial public offering market might indeed by subject to a 'lemons' problem [see Akerlof (1970)]. This is because each issuing firm, which will go public only once, has no incentive to leave money on the table. However, if there is an intermediary with an incentive to appropriately price issues, then it is possible to overcome this potential problem. In the market for initial public offerings, this intcrmediary is the managing underwriter for an issue. This role for investment bankers is possible because an investment banking firm underwrites many offerings over time. Because of the repeat business with potential purchasers, an investment banker can develop a reputation and earn a return on this reputation. ${ }^{5}$

\footnotetext{
${ }^{5}$ See Allen (1984), Klein and Leffler (1981) or Rogerson (1983) for models where there is quality variation. A closely related model is Telser's (1980) theory of self-enforcing agreements. In the context of Telser's model, the two parties voluntarily contracting are a representative investor and an investment banker. Gilson and Kraakman (1984, pp. 613-621) discuss the importance of investment bankers' reputations.
} 
For an investment banker to find that it is in its interest to enforce the underpricing equilibrium when setting an offering price, there are three necessary conditions. The first condition is that the investment banker is uncertain what the market price of the stock once it starts trading will be, for otherwise the underwriter could perfectly price each and every issue, and there would be no winner's curse problem facing investors. ${ }^{6}$ The second condition is that the investment banker has non-salvagable reputation capital at stake, on which it can earn a return. The third condition is that the ability to earn a return on this non-salvagable reputation capital drops if the underwriter 'cheats' by underpricing too much or too little.

The first necessary condition is specific to the underpricing equilibrium in the market for initial public offerings. The other two necessary conditions are the standard conditions in the recent literature on reputation and product quality. They can be summarized by the statement that the net present value of future quasirents that a reputable investment banker can expect to earn exceeds the short-run gain from opportunistic behavior. This willingness to not behave opportunistically is what is meant, we feel, by having a good reputation. An investment banker will find that it is not in its interest to behave opportunistically if it has a stock of reputation capital ('goodwill') built up, on which it is earning a return in the form of, for example, having lower distribution costs, or being able to charge higher underwriting fees. ${ }^{7}$

This argument produces our second proposition. If the underpricing equilibrium is enforced by investment bankers with reputation capital at stake, any investment banking firm that cheats must lose customers, for otherwise there would be no incentive not to cheat. If, on average, an investment banker does not underprice its offerings enough, the average initial return will be too low, and investors subject to the winner's curse problem will cease doing business with this underwriter. On the other hand, if an investment banker underprices its offerings too much, so that the average initial return is too high, potential issuers will cease using this underwriter. Whether or not an underwriter will lose its entire business or not depends upon the 'quality' of information - i.e., whether or not potential clients can discern whether mispricing is systematic or due to random events in a small sample. [See Rogerson (1983) for an elucidation of this point.] Since underwriters that underprice either too much or too little should lose business, we have a testable implication:

Proposition 2. Underwriters whose offerings have average initial returns that are not commensurate with their ex ante uncertainty lose subsequent market share.

\footnotetext{
${ }^{6}$ While underwriters may have a relatively good idea of the state of demand for an issue by the time they set an offering price, they aren't able to forecast demand perfectly. It is not unusual to see an underwriter misestimate the aftermarket price by 20 percent or more.

${ }^{7} \mathrm{~A}$ reputable investment banker can get a higher offering price for an issue, so that a proportional fee schedule will result in a higher total commission for the underwriter. Firm-specific capital discourages opportunistic behavior.
} 


\section{Data}

In section 2, we derived a proposition relating the degree of expected underpricing of an initial public offering to the ex ante uncertainty of the issue. In section 3, we argued that underwriters who do not enforce this underpricing equilibrium should lose market share. This section provides a description of the proxies that we use for ex ante uncertainty, and defines market share. We also describe the sample with which we test our propositions.

Proposition 1 relates the distribution of initial returns to ex ante uncertainty. ${ }^{8}$ The proxies that we use to test this proposition are (i) the log of one plus the number of uses of proceeds listed in the prospectus, and (ii) the inverse of the gross proceeds.

The content of the Uses of Proceeds section in a prospectus can range from no mention of specific uses to detailed cost allocations for the firm's expected production-investment decisions. We have compiled the number of specific uses for which a dollar amount is quantified in each prospectus, a number which varies from 0 (for several secondary offerings where the issuing firm receives none of the proceeds) to 32 among the firms going public.

The number of uses of proceeds listed is a proxy for ex ante uncertainty largely as a result of Securities and Exchange Commission (SEC) regulation. Firms appear to be reluctant to give highly detailed specifications of what they will do with their net proceeds for two reasons: increased exposure to legal liability, and disclosure of proprietary information to competitors. The SEC, however, requires more speculative issues to provide relatively detailed enumerations of the uses of proceeds, while not requiring more established issuers to be very explicit. ${ }^{9}$ As a result of this regulation, issues for which there is

\footnotetext{
${ }^{8}$ Initial returns are defined as $\left(v_{t}-O P\right) / O P$, where $O P$ is the offering price and $v_{t}$ is the closing bid price on the first day of public trading. In some cases, the closing bid price on the first day of trading is not available. In these situations, the first recorded closing bid price has been used. The closing bid prices were taken from the Daily Stock Price Record for the firms listed on NASDAQ. For the 9.9 percent of firms not listed on the NASDAQ, the following data sources (in order of priority) were employed:

(1) Going Public: The IPO Reporter;

(2) National Stock Summary;

(3) lead underwriter;

(4) issuing firm's officer for stockholder relations.

These prices are generally within a few days of the offering date, so that market movements can be presumed to have had only a minor influence. None of our initial return calculations adjust for market movements. The average initial return was 14.1 percent for the second subperiod, while the average daily market return was less than 0.1 percent, as measured by the dividend-inclusive S\& $P$ 500 index. Consequently, adjustments for market movements in the initial return calculations would result in only minor changes.

${ }^{9}$ The SEC's Regulation S-K governs the required disclosures in the non-financial portions of the prospectus. The differential requirements are a result of de facto case precedents, rather than explicit regulations. As Schneider, Manko and Kant (1983, pp. 10-11) state: 'In the course of administration over the years, the Commission has given specific content to the general disclosure requirements. It often requires disclosures on a number of points within the scope of the [registration] form bui not explicitly covered by the form itself.'
} 
greater ex ante uncertainty tend to have a greater number of the uses of proceeds listed.

Our second proxy for ex ante uncertainty is the inverse of the gross proceeds raised in an offering. This captures the empirical regularity that smaller offerings are more speculative, on average, than larger offerings. ${ }^{10}$ With the range of gross proceeds being $\$ 100,000$ to $\$ 109,854,000$, expressed in terms of 1982 purchasing power, the reciprocal has a range of 0.0000000091 to 0.00001 .

To test our propositions, we use a data set of all firms that conducted SEC-registered initial public offerings of common stock during 1977-82, a total of 1028 firms. ${ }^{11}$ We split this sample into two approximately equal-sized subperiods for our tests. The first subperiod includes the 483 firms that went public between 1977 and the first quarter of 1981. The second subperiod includes the 545 firms that went public between the second quarter of 1981 and 1982. These subperiods have different lengths because the rate at which firms went public was much lower during the first 3 years of the sample than during the last 3 years.

We divide the sample into two subperiods for two reasons. The first reason is that Proposition 2 predicts changing market shares, so dividing the sample into subperiods is required in order to test this proposition. The second reason is that there was a pronounced 'industry effect' for natural resource issues from January 1980 to March 1981, as documented by Ritter (1984). Rather than resorting to ad hoc industry effect dummy variables, to test Proposition 1 we restrict ourselves to the 1981.II-1982 subperiod during which the relation between risk and initial return does not appear to be subject to industry effects.

In our tests of Proposition 2, we analyze whether there is a relation between mispricing by investment bankers and subsequent change in market share. For these tests, we define an investment banker's market share in a subperiod as the fraction of initial public offerings that the underwriter managed or comanaged, where co-managed offerings are counted in net terms, i.e., two offerings co-managed with another underwriter give the same market share as

\footnotetext{
${ }^{10}$ See Ritter (1985, table 6).

${ }^{11}$ Initial Public Offerings registered under Regulation A (common stock offerings below $\$ 1,500,000$ ) are not included in this count. The primary data source is Howard and Co. 's Going Public: The IPO Reporter. In addition to the 1028 initial public offerings in the 1977-82 period, Going Public lists 47 other offerings that we exclude due to one of four special features. These features are discussed in Ritter (1984, pp. 216-217. footnote 2). Of relevance to this paper is that of the 47 excluded, 36 were removed due to not using an underwriter. Firms not using an underwriter fall into two categories: bank stocks and very small offerings. Both categories tend to be sold locally, and many fail to develop an active public market. Of the non-bank, non-underwritten offerings, the average gross proceeds is only $\$ 1.5$ million. as contrasted with an average of $\$ 6.6$ million for the 1028 firms in our sample (neither of these figures has been adjusted for price level changes). We view these non-underwritten offerings as equivalent in many respects to private placements. (In particular, frequently no active public market develops.) Consequently, we exclude these firms on the grounds that they represent something substantially different from going public. We do not view a non-underwritten offering as a viable alternative to the use of an investment banker for most firms going public. Of course, this is consistent with our theory in section 3.
} 


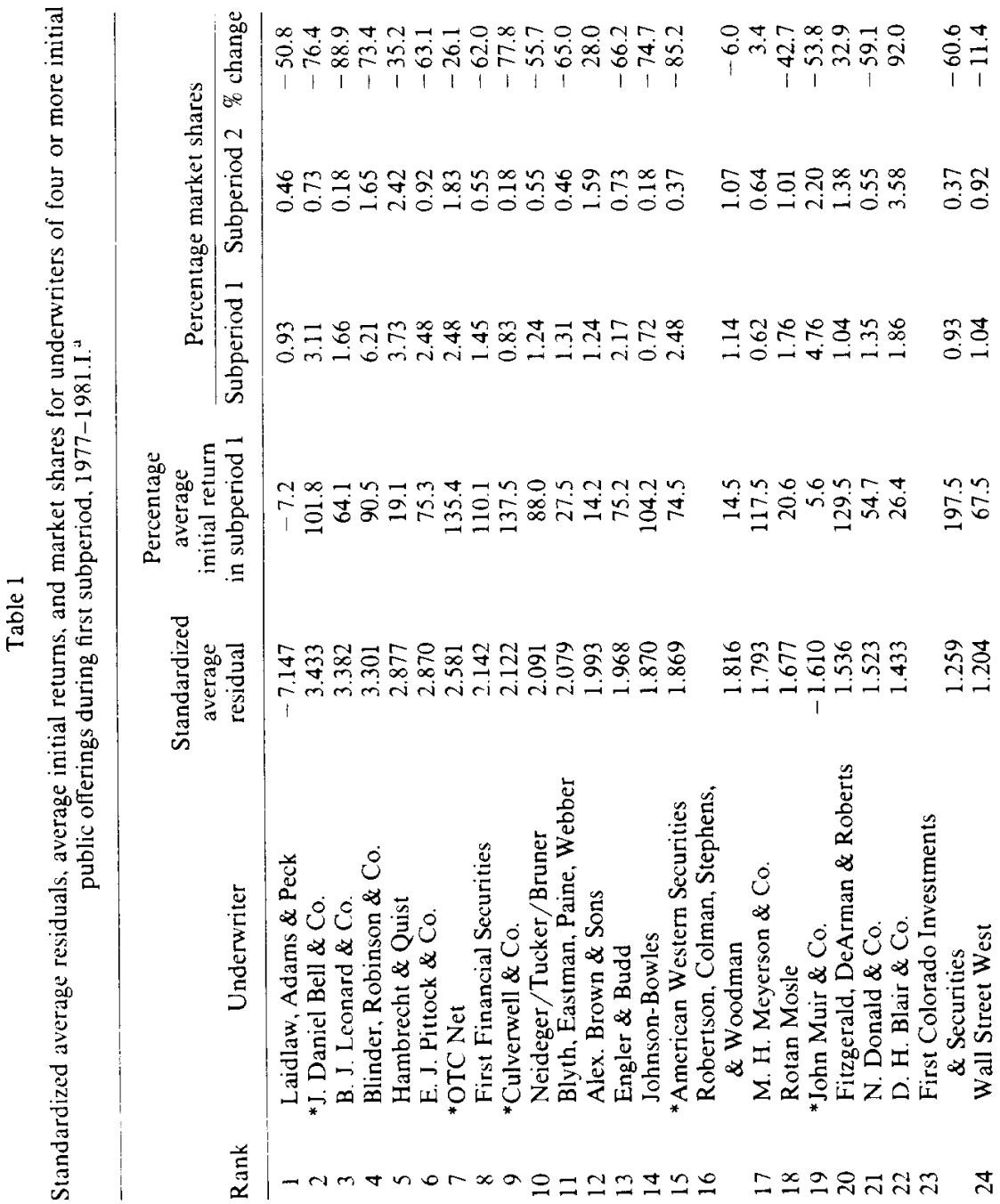




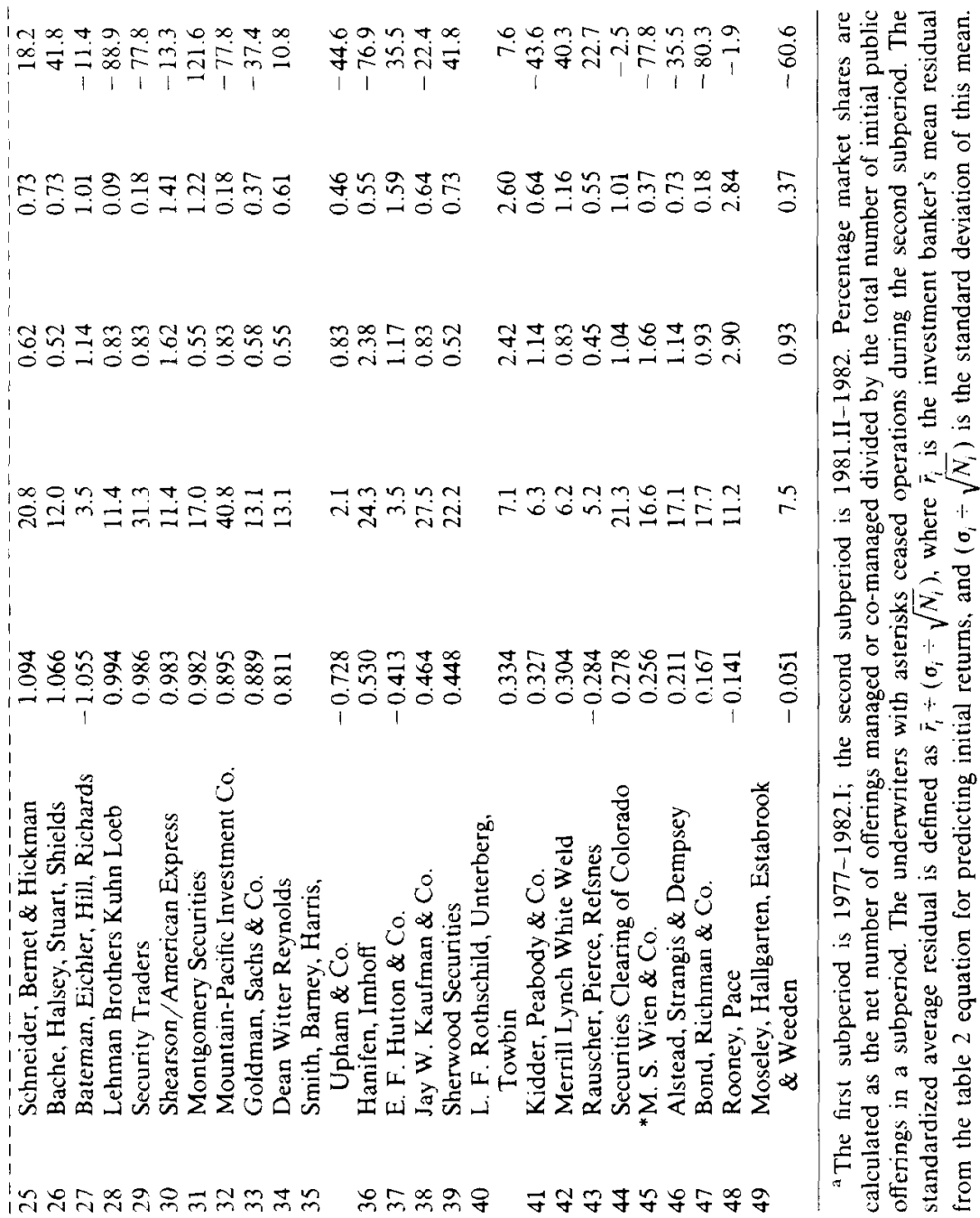


one solely-managed offering. Approximately one quarter of all offerings are co-managed, and three quarters are solely managed. (We have also duplicated our tests using a definition of market share where offerings are weighted by the gross proceeds involved. The qualitative results are similar to those that we report in the next section.) In table 1 , we provide data on the average initial returns and market shares for 49 major underwriters of initial public offerings.

\section{Empirical evidence and interpretation of the results}

To test whether there is a positive relation between initial return and ex ante uncertainty, as predicted by Proposition 1, we regress initial returns on two proxies for ex ante uncertainty, using the 545 firms in the second subperiod. We use weighted least squares (WLS) because of the heteroscedasticity that is present in an ordinary least squares regression. This heteroscedasticity should be present, since higher ex ante uncertainty should be reflected in a greater dispersion of initial returns. To get efficient parameter estimates in our empirical work, however, homoscedastic disturbance terms are desired. ${ }^{12}$ Consequently, we weight our regression by a factor which is proportional to the precision of the disturbance terms. In particular, we multiply both left-hand and right-hand side variables by $\log [1000+$ sales $]$, where sales is the annual revenues of the issuing firm in the 12 months prior to going public, expressed in terms of 1982 purchasing power. Since we are multiplying by this weight, issuing firms with no operating histories are given less weight in the regressions than more established firms for which the ex ante uncertainty is likely to be less. With the range of sales being 0 to $\$ 867,806,000$, the range of the weighting factor is from 6.91 to 20.58 .

In table 2, we report the results of a WLS regression using initial returns as the dependent variable. As explanatory variables, we use the log of one plus the number of uses of proceeds, and the reciprocal of the gross proceeds expressed in terms of 1982 purchasing power. ${ }^{13}$ The positive coefficients on

\footnotetext{
${ }^{12}$ Our results are nearly identical using ordinary least squares rather than wcighted least squares. Furthermore, the WLS results are robust to a variety of weighting factors.

${ }^{13}$ The regression results that we report in table 2 have been selected from a series of unreported regressions undertaken in preliminary work. This selection process makes interpretation of the $t$-statistics difficult. During our preliminary work, we ran a regression including, as explanatory variables, $\log (1+$ number of uses of proceeds $)$, the reciprocal of gross proceeds, $\log (1+$ age $)$, $\log (1+$ sales $)$ and $\log (1+$ number of risk factors $)$. The $F$-statistic on this regression is 13.83 , which is significant at the $0.001 \alpha$-level with $(5,539)$ degrees of freedom. The existence of multicollinearity in the independent variables of this all-inclusive regression led to the selection of our parsimonious model. In addition, we considered the daily aftermarket standard deviation as a proxy for ex ante uncertainty. The reason that we don't use the daily aftermarket standard deviation in our reported tests, in spite of its obvious appeal as a proxy for ex ante uncertainty, is that it is unavailable for the 9.9 percent of the firms that weren't listed on NASDAQ. These omitted firms are primarily 'penny stocks'. Excluding these firms makes it difficult to come up with an absolute standardized average residual for the underwriters who specialized in penny stocks. Consequently, it is difficult to test our hypothesis regarding changing market shares.
} 
Tablc 2

Weighted least squares regression results with initial return as the dependent variable. ${ }^{a}$

\begin{tabular}{cccc}
\hline Constant & $\begin{array}{c}\text { Log( } 1+\text { number of } \\
\text { uses of proceeds })\end{array}$ & $\begin{array}{c}\text { Reciprocal of } \\
\text { gross proceeds }\end{array}$ & $R^{2}$ \\
\hline-0.0268 & 0.0691 & 83,578 & 0.07 \\
$(0.0360)$ & $(0.0209)$ & $(18,561)$ & \\
\hline
\end{tabular}

\begin{abstract}
${ }^{\text {a }}$ Standard errors in parentheses. The sample is comprised of all 545 underwritten S.E.C.-registered initial public offerings from April 1981 to December 1982. The weighting factor is log $[1000+$ sales $]$, where sales is the most recent 12 -month revenues for the issuing firm expressed in terms of 1982 purchasing power. The means of the variables are: 13.25 for the weighting factor, 1.74 for the log of one plus the number of uses of proceeds and 0.000000423 for the reciprocal of gross proceeds. Gross proceeds is measured in dollars of 1982 purchasing power. The average initial return is 0.141 , or 14.1 percent.
\end{abstract}

these variables indicate that investors interpret these measures as positively correlated with ex ante uncertainty. The coefficient of 83,578 on the inverse of gross proceeds indicates that smaller offerings, ceteris paribus, have substantially higher average initial returns.

We interpret the results in table 2 as showing that, as Proposition 1 states, there is a positive relation between ex ante uncertainty and expected underpricing. ${ }^{14}$

It is worth noting that the $R^{2}$ is quite low at 0.07 . This is as it should be. If the $R^{2}$ was high, it would imply that the actual initial return on an offering is predictable. The theory states that there is a positive relation between ex ante uncertainty and expected initial return. The reason for this positive relation is that it is difficult for investors to predict the actual initial return on a high-risk issue, giving rise to the winner's curse problem, even though the average initial return in a large sample can be predicted with reasonable accuracy. Consequently, the low $R^{2}$ is consistent with Proposition 1.

To test Proposition 2, we have computed the market shares of all underwriters of four or more initial public offerings during the first subperiod. ${ }^{15}$ These underwriters are listed in table 1 . In fig. 1, we graph the average initial

\footnotetext{
${ }^{14} \mathrm{We}$ are, of course, testing a joint hypothesis. The joint hypothesis is that there is a positive relation between ex ante uncertainty and average initial returns, and that we have adequate proxies for ex ante uncertainty

${ }^{15}$ We restrict our analysis to underwriters of 4 or more offerings because, given the variation in initial returns, it is difficult to view the fringe underwriters of 3 or fewer offerings as having much of a track record to analyze. The qualitative conclusions do not change if the cutoff is at 3 or 5 instead of 4 .
} 


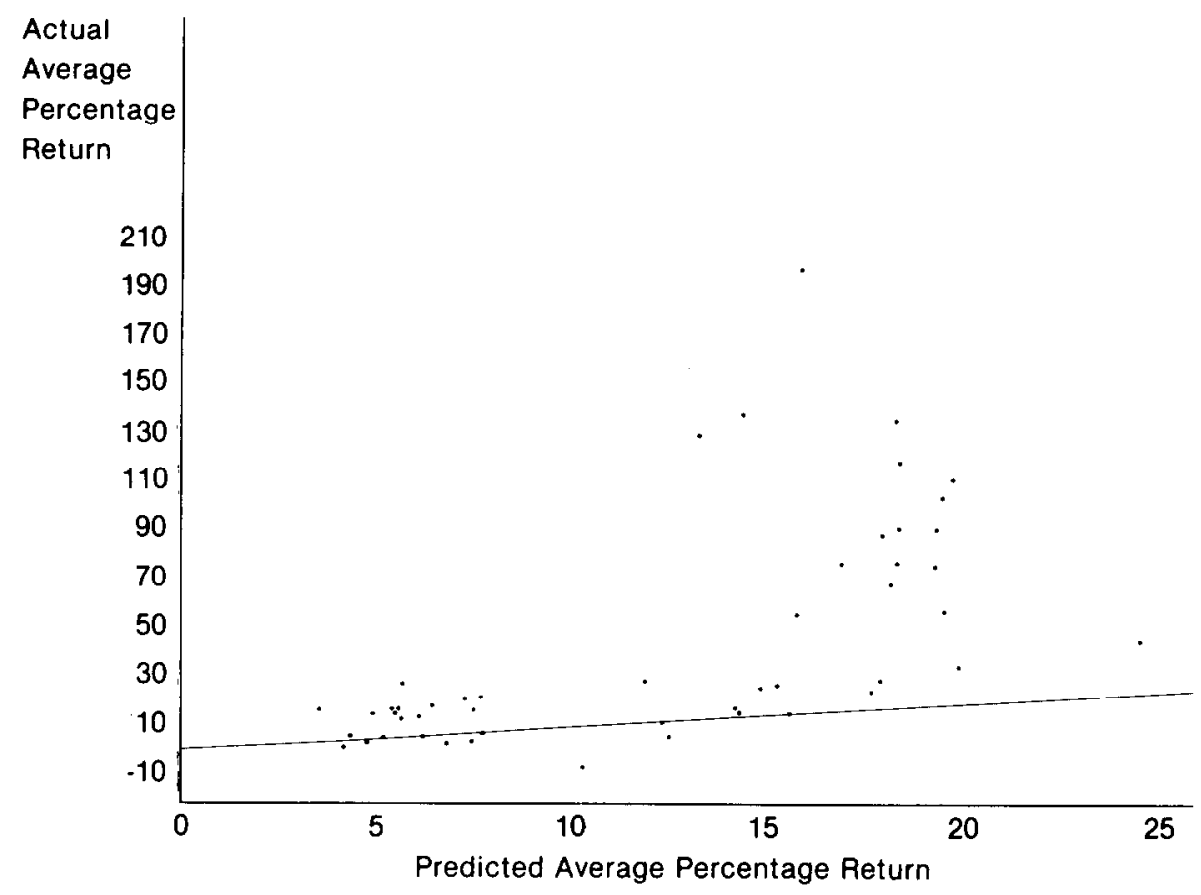

Fig. 1. Relation between the actual average percentage initial return (vertical axis) and the predicted average percentage initial return (horizontal axis) for the 49 underwriters of 4 or more issues during 1977-1981.I. Predicted average initial returns are based upon regression results reported in table 2 . The line drawn has a slope of one and an intercept of zero.

return and average predicted initial return during the first subperiod for each of the 49 investment bankers that meet this criterion. The predicted initial returns are computed using the table 2 regression, which was estimated over the second subperiod. Note that the predicted average initial returns show a rather wide range, which is duc to the tendency of underwriters to specialize in offerings of a given 'quality class'. ${ }^{16}$ Also plotted is a line with a slope of one along which all 49 points would lie if every investment banking firm enforced the underpricing equilibrium with no error.

To analyze the relation between market share changes and mispricing, we define the 'absolute standardized average residual' as follows:

For each firm $j$ taken public by underwriter $i$, we first compute a predicted initial return $\mathrm{E}\left(p_{i j}\right)$ based upon the regression coefficients reported in table 2. We subtract this predicted initial return from the actual initial return, $p_{i j}$, to

\footnotetext{
${ }^{16}$ The specialization of underwriters by quality of offering is a very strong tendency. Titman and Trueman (1985) present a model predicting this. Ritter (1985) finds that underwriters also tend to specialize by contract, where the choices are between firm commitment and best efforts contracts.
} 
get the residual for each issue:

$$
r_{i j}=p_{i j}-\mathrm{E}\left(p_{i j}\right)
$$

For each underwriter, we then compute the average residual

$$
\bar{r}_{i}=\frac{1}{N_{i}} \sum_{j=1}^{N_{i}} r_{i j}
$$

where $N_{i}$ is the number of offerings taken public by underwriter $i$.

To discern whether or not, in a statistically significant sense, an underwriter is mispricing its issues, we divide $\bar{r}_{i}$ by $\sigma_{i} / \sqrt{N_{i}}$, the standard deviation of the mean initial return, to get our standardized average residual. Dividing by $\sigma_{i} / \sqrt{N_{i}}$, where $\sigma_{i}$ is the standard deviation of the residuals of underwriter $i$, controls for the fact that, as an underwriter's track record becomes longer, a potential issuer or investor is able to discern whether or not it is 'off the line', with reference to fig. 1 , more clearly. The absolute standardized average residual is the absolute value of the standardized average residual.

In table 1, we have ranked underwriters in terms of their absolute standardized average residuals. The 24 underwriters with the largest absolute standardized average residuals we refer to as pricing 'off the line'. The other 25 underwriters are referred to as pricing 'on the line'. In table $3 \mathrm{a}$, we report the market shares by subperiod for the categories of underwriters pricing off the line and on the line. For the 24 underwriters off the line, their market share fell from 46.6 percent in the first subperiod to 24.5 percent in the second subperiod, a 47 percent decrease. The 25 firms pricing on the line saw their market share fall by only 23 percent. (Both of these groups had their market shares eroded by increased competition during the second subperiod, primarily from 'major bracket' investment banking firms that previously had not had a major presence in the initial public offering market.)

Also reported in table $3 \mathrm{a}$ is the fact that 5 out of the 24 underwriters pricing off the line in the first subperiod ceased operations during the second subperiod. (They went out of business - they didn't merge.) This contrasts with only 1 out of 25 among those underwriters pricing on the line. A formal statistical test of the proposition that the probability of ceasing operations is independent of the categorization of an underwriter involves the hypergeometric distribution, which assumes 'sampling without replacement'. ${ }^{17}$ For 6 out of

\footnotetext{
${ }^{17}$ The hypergeometric distribution, which is described in most introductory mathematical statistics and probability textbooks, gives

$$
\operatorname{prob}(x)=\left(\begin{array}{c}
K \\
x
\end{array}\right)\left(\begin{array}{c}
M-K \\
n-x
\end{array}\right) /\left(\begin{array}{c}
M \\
n
\end{array}\right),
$$

where $x$ is the number of underwriters ceasing operations in a sample of size $n(24), M$ is the number of underwriters (49), and $K$ is the number of underwriters ceasing operations in the population (6). Given these parameters, the probability that $x \geq 5$ is 0.0856 .
} 
Table $3 \mathbf{a}$

Change in market share by underwriter category. ${ }^{a}$

\begin{tabular}{|c|c|c|c|}
\hline \multirow{2}{*}{$\begin{array}{l}\text { Underwriter performance } \\
\text { 1977-1981.I }\end{array}$} & \multicolumn{2}{|c|}{ Market share } & \multirow{2}{*}{$\begin{array}{c}\text { Fraction ceasing } \\
\text { operations during } \\
\text { 1981.II-1982 }\end{array}$} \\
\hline & 1977-1981.I & 1981.II-1982 & \\
\hline $\begin{array}{l}24 \text { underwriters } \\
\text { 'off the line' }\end{array}$ & $46.6 \%$ & $24.5 \%$ & $5 / 24$ \\
\hline $\begin{array}{l}25 \text { underwriters } \\
\text { 'on the line' }\end{array}$ & $27.2 \%$ & $21.0 \%$ & $1 / 25$ \\
\hline All other underwriters & $26.2 \%$ & $54.5 \%$ & $11 / 197$ \\
\hline
\end{tabular}

${ }^{a}$ Market share computed by allocating a fraction of one-half or one-third to each co-manager of an initial public offering if 2 or 3 underwriters co-managed an offering. Market share computations are based upon all 1028 firms going public during 1977-82 using an underwriter. Each of the 49 underwriters evaluated managed or co-managed at least 4 initial public offerings during the 1977-1981.I subperiod. They are listed in table 1. The $26.2 \%$ of offerings done by other underwriters ( 126.67 out of 483 offerings) in the first subperiod used 104 different underwriters. For the $54.5 \%$ of offerings done by other underwriters (297 out of 545 offerings) in the second subperiod, 161 different underwriters were used. For the 1977-82 period as a whole, 246 underwriters managed or co-managed at least one offering.

Table $3 b$

Ordinary least squares regression results with percentage change in market share as dependent variable. ${ }^{a}$

\begin{tabular}{cccc}
\hline Constant & $\begin{array}{c}\text { Absolute standardized } \\
\text { average residual }\end{array}$ & $R^{2}$ & $N$ \\
\hline-12.85 & -10.83 & 0.07 & 49 \\
$(10.54)$ & $(5.59)$ & & \\
\hline
\end{tabular}

\footnotetext{
${ }^{a}$ Standard errors in parentheses. The mean of the dependent variable is -28.4 percent, with a standard derivation of 49.3. Market shares calculated by dividing the net number of initial public offerings of underwriter $i$ by the total number of offerings in each subperiod. Co-managed offerings counted as one-half or one-third. The mean of the explanatory variable is 1.42 , with a standard deviation of 1.26. The absolute standardized average residual is defined as $\left|\bar{r}_{i} \div\left(\sigma_{i} \div \sqrt{N_{i}}\right)\right|$, where $\bar{r}_{i}$ is the investment banker's mean residual from the table 2 equation for predicting initial returns, and $\left(\sigma_{1}-\sqrt{N_{i}}\right)$ is the standard deviation of this mean.
} 
49 underwritcrs ceasing operations, the probability that, in a random sample of 24 underwriters, 5 or more went out of business in the second subperiod is 9 percent.

In table $3 \mathrm{~b}$ instead of categorizing underwriters as to whether or not they are off the line, we regress the percentage change in market share on absolute standardized average residuals for the 49 underwriters of interest. The slope coefficient of -10.83 in this regression implies that as the value of the explanatory variable changes from one standard deviation below the mean to one standard deviation above, the expected market share drops by 27.3 percent, an economically meaningful change. With a $t$-statistic of 1.94 on the slope coefficient, the one-tailed $p$-value is 3 percent.

While these tests of Proposition 2 are not independent, we interpret all of these results as providing support for the proposition that the market does penalize underwriters who cheat on the underpricing equilibrium by underpricing too much or too little.

\section{Summary and conclusions}

In this paper we have argued that there is a positive relation between the ex ante uncertainty about an initial public offering's value and its expected initial return. Using two proxies for this uncertainty, we have provided empirical evidence in support of this proposition. An implication of this finding is that, if the level of ex ante uncertainty is endogenous, an issuing firm has an incentive to reduce this uncertainty by voluntarily disclosing information.

We have also argued that the mechanism by which this underpricing equilibrium is enforced is via the investment banking industry. In order for investment bankers to find it in their interest to maintain the underpricing equilibrium, three conditions are necessary. These are that (i) the underwriters are not perfect forecasters of the aftermarket price, (ii) each underwriter must have non-salvagable reputation capital at stake on which it is earning a return, and (iii) any underwriter who cheats by, on average, pricing 'off the line' must lose clients. We find that investment bankers pricing off the line in one subperiod do in fact lose market share in the subsequent subperiod, although the relation is a noisy one. We interpret these empirical findings as supporting our argument that investment bankers enforce the underpricing equilibrium.

\section{Appendix: Underpricing in an asymmetric information model}

This appendix provides a formal model of the underpricing of initial public offerings. It uses the asymmetric information model introduced by Rock (1982,1986). In this model, an issuing firm is uncertain about its value per share. It must set an offering price, $O P$, however, and then solicit purchase 
orders from the public at this price. If the issue is oversubscribed, the shares are allocated in proportion to the excess demand. Investors are also uncertain about the value of a share, but for a cost $c$, an investor can become informed about the price per share, $v$, that will prevail once the stock starts trading. Investors who do not incur this cost are termed uninformed investors, and their knowledge about $v$ is limited to knowing its probability density function, denoted by $f(v)$. Issuing firms and their investment bankers are assumed to be among the uninformed. (This last assumption's purpose is to make the issuing parties uncertain about the true value per share. Otherwise, there would be no need to underprice.)

Informed investors, each of whom has investable wealth of $W-c$, will submit purchase orders only if the offering is underpriced $(v>O P)$. This behavior by informed investors creates an adverse selection problem for uninformed investors. For underpriced issues $(v>O P)$, both informed and uninformed investors will submit purchase orders, and uninformed investors will be allocated only some of the shares that trade at a premium in the aftermarket. For overpriced issues $(v<O P)$, however, only uninformed investors submit purchase orders, so the uninformed are allocated 100 percent of all the issues that trade at a discount in the aftermarket. Consequently, if an uninformed investor is allocated shares in an initial public offering, there is a greater than usual chance that the issue will start trading at a discount in the aftermarket. In other words, for an uninformed investor, the expected return conditional upon being allocated shares is less than the expected return conditional upon submitting a purchase order. But an uninformed investor will participate in the market only if the expected return conditional upon being allocated shares is non-negative. This can only happen if, on average, issuers underprice their shares. The owners of a firm going public, who typically have a large proportion of their wealth invested in the firm, would be willing to pay this price if they are sufficiently risk-averse.

With the number of investors who choose to become informed endogenous [as in Rock (1982, ch. II)], the equilibrium conditions converge to two equations. These two conditions are (i) zero expected profits for informed investors and (ii) zero expected profits for uninformed investors. The first condition can be expressed as

$$
N \cdot c=\alpha \int_{O P}^{\infty} n(v-O P) f(v) \mathrm{d} v,
$$

where $N$ is the number of informed investors, $c$ is the cost per investor of becoming informed, $\alpha$ is the fraction of shares allocated to informed investors when an offering is underpriced, $O P$ is the offering price, $n$ is the number of shares, and $v$ is the after-market price. The left-hand side is the aggregate cost of becoming informed. The right-hand side is the proportion of each under- 
priced issuc that will be allocated to informed investors, multiplied by the gross profits on underpriced issues. The product of these gives the gross profits earned by informed investors.

The second equilibrium condition, zero expected profits for the uninformed, occurs when the aggregate losses on overpriced issues (the uninformed get all of the losing issues) equal the uninformed's share of the gross profits on underpriced issues:

$$
\int_{0}^{O P} n(O P-v) f(v) \mathrm{d} v=(1-\alpha) \int_{O P}^{\infty} n(v-O P) f(v) \mathrm{d} v
$$

Eqs. (1) and (2) hold for any probability density function for the aftermarket price. Between them, they imply that, due to the winner's curse problem facing uninformed investors, all of the profits accruing to investors due to underpricing will be received by informed investors. Investors seeking these profits, however, will incur sufficient costs so that the aggregate costs of becoming informed equal the amount of money 'left on the table':

$$
N \cdot c=\int_{0}^{\infty} n(v-O P) f(v) \mathrm{d} v=n[\mathrm{E}(v)-O P]
$$

In eq. (3), the number of investors who choose to become informed, $N$, determines the required amount of underpricing, $\mathrm{E}(v)-O P$. The decision to become informed is analogous to the decision to buy a call option giving the right to buy shares if $v>O P$. Just as with standard option pricing analysis, this option is worth more, ceteris paribus, the greater is the dispersion of $v$, which for new issues corresponds to greater ex ante uncertainty. Since the price of the option is the fixed cost $c$, the greater is the ex ante uncertainty, the greater is the number of investors who choose to become informed. This is why there is a positive relation between ex ante uncertainty and the degree of underpricing of initial public offerings.

We now formally demonstrate, under fairly restrictive conditions, our underpricing result. As the above argument indicates, however, we believe the result is much more general. In this demonstration, let the fraction of underpriced issues allocated to informed investors, $\alpha$, be given by

$$
\alpha=\frac{N(W-c)}{N(W-c)+O P \cdot n},
$$

where $(W-c)$ is the investment per informed investor (no borrowing or short-selling is allowed). This expression assumes that aggregate uninformed demand is sufficient to fully subscribe an issue. Consequently, for underpriced issues, aggregate informed demand is given by $N(W-c)$ and aggregate uninformed demand is equal to $O P \cdot n$, resulting in eq. (4). 
While eqs. (1), (2), and (3) hold for any probability density function for the aftermarket price, $f(v)$, comparative static results do not necessarily hold for any arbitrary probability density function (p.d.f.). Our results hold for p.d.f.'s of the increasing failure rate class, an example of which is the uniform distribution, which we use to generate comparative static results. Consequently, let $f(v)=1 /(b-a)$, on $[a, b], b>a \geq 0$, where $a$ replaces 0 and $b$ replaces $\infty$ in the limits of integration in eqs. (1) and (2).

Performing the integration in eq. (1) using a uniform distribution, and solving for $N / n$, the number of informed investors per share, results in

$$
\frac{N}{n}=\left(\frac{1}{b-a}\right)\left(\frac{1}{2 c}\right)(O P-b)^{2}-\frac{O P}{W-c}
$$

Performing the integrations in eq. (2) results in

$$
\frac{N}{n}=\frac{O P}{W-c}\left(\frac{O P-b}{O P-a}\right)^{2}-\frac{O P}{W-c}
$$

Eqs. $\left(1^{\prime}\right)$ and $\left(2^{\prime}\right)$ hold for parameter values of $W, a, b, c$ and $n$ such that the number of informed investors, $N$, is strictly positive. If this is not the case, there is no adverse selection against the uninformed. If there is no adverse selection, a pooling equilibrium would exist in which there is no underpricing.

In the two-equation system given by $\left(1^{\prime}\right)$ and $\left(2^{\prime}\right)$, the endogenous variables are $N$, the number of informed investors, and $O P$, the optimal offering price. [In Rock (1982, ch. II) the number of informed investors, $N$, is endogenous. This is not the case with the analysis in Rock (1986).] Equating cqs. (1') and $\left(2^{\prime}\right)$ results in a quadratic equation for the issuing firm's optimal offering price:

$$
O P^{2}-2[a+(b-a) C] O P+a^{2}=0
$$

where $C \equiv c /(W-c) . C$ is the cost of becoming informed as a fraction of the investable wealth of the informed. The quadratic equation (5) has roots of

$$
O P_{1,2}=a+(b-a) C \pm \sqrt{2 a C(b-a)+C^{2}(b-a)^{2}}
$$

Of the two roots, the $-\sqrt{-}$ root is not economically meaningful, in that the offering price would be less than $a$, the lower limit of the p.d.f. for the aftermarket price. This would mean that there is no possibility of a loss for any investor submitting a purchase order. Thus, the (unique) offering price is given by the $+\sqrt{\cdot}$ root.

Before analyzing the effect of a decrease in the dispersion of possible aftermarket prices on the optimal $O P$, it will be useful to rewrite expression 
(6), noting that

$$
a=\frac{b+a}{2}-\frac{b-a}{2} \text { where } \frac{b+a}{2}=\mathrm{E}(v) .
$$

The equilibrium offering price is

$$
\begin{aligned}
O P= & \mathrm{E}(v)+\left(C-\frac{1}{2}\right)(b-a) \\
& +\sqrt{2 \mathrm{E}(v) C(b-a)-C(b-a)^{2}+\overline{C^{2}(b-a)^{2}} .} .
\end{aligned}
$$

Note that $C$ must be less than one-half, since $O P$ is bounded by $a$ below and $\mathrm{E}(v)$ above.

We can now prove our fundamental underpricing proposition:

Proposition 1. The greater is the ex ante uncertainty about the value of an issue, the greater is the expected underpricing.

Proof. Holding E(v) constant, we want to demonstrate that

$$
\frac{\partial O P}{\partial(b-a)}<0
$$

Differentiating eq. (7), we have

$$
\frac{\partial O P}{\partial(b-a)}=C-\frac{1}{2}+\frac{C \mathrm{E}(v)-C(b-a)+C^{2}(b-a)}{\sqrt{2 \mathrm{E}(v) C(b-a)-C(b-a)^{2}+C^{2}(b-a)^{2}}} .
$$

Since $a<O P<E(v)$, from eq. (7) we know that

$$
0>\left(C-\frac{1}{2}\right)(b-a)+\sqrt{2 \mathrm{E}(v) C(b-a)-C(b-a)^{2}+C^{2}(b-a)^{2}},
$$

which can be rewritten as

$$
0>\left(C-\frac{1}{2}\right)(b-a)+\frac{2 \mathrm{E}(v) C(b-a)-C(b-a)^{2}+C^{2}(b-a)^{2}}{\sqrt{2 \mathrm{E}(v) C(b-a)-C(b-a)^{2}+C^{2}(b-a)^{2}}} .
$$

Cancelling the common $(b-a)$ term in the numerator, we have

$$
0>\left(C-\frac{1}{2}\right)+\frac{2 \mathrm{E}(v) C-C(b-a)+C^{2}(b-a)}{\sqrt{2 \mathrm{E}(v) C(b-a)-C(b-a)^{2}+C^{2}(b-a)^{2}}} .
$$


The right-hand side of eq. (9) is identical to eq. (8), except for the $2 \mathrm{E}(v) C$ term. Since eq. (9) is negative, eq. (8) must be negative, since $2 \mathrm{E}(v) C>\mathrm{E}(v) C$. This completes the proof.

This model is based upon the institutional characteristics of firm commitment offerings. Firm commitment offerings were used to raise $87 \%$ of the gross proceeds of initial public offerings in the U.S. during the 1977-82 period that we use in our empirical tests.

\section{References}

Akerlof, G.A., 1970, The market for 'lemons': Quality uncertainty and the market mechanism, Quarterly Journal of Economics 84, 488-500.

Allen, F., 1984, Reputation and product quality, Rand Journal of Economics 15, 311-327.

Gilson, R.J. and R. Kraakman, 1984, The mechanisms of market efficiency, Virginia Law Review $70,549-644$.

Going Public: The IPO Reporter, 1977-82, Published weekly (Howard \& Co., Philadelphia, PA).

Ibbotson, R.G., 1975, Price performance of common stock new issues, Journal of Financial Economics 3, 235-272.

Ibbotson, R.G. and J.J. Jaffe, 1975, 'Hot issue' markets, Journal of Finance 30, 1027-1042.

Klein, B. and K.B. Leffler, 1981, The role of market forces in assuring contractual performance, Journal of Political Economy 89, 615-641.

National Stock Summary, 1977-82 (National Quotation Bureau, New York).

Ritter, J.R., 1984, The 'hot issue' market of 1980, Journal of Business 57, 215-240.

Ritter, J.R., 1985, The choice between firm commitment and best efforts contracts, Unpublished working paper (University of Michigan, Ann Arbor, MI).

Rock, K., 1982, Why new issues are underpriced, Unpublished $\mathrm{Ph}$.D. dissertation (University of Chicago, Chicago, IL).

Rock, K., 1986, Why new issues are underpriced, Joumal of Financial Economics, this issue.

Rogerson, W.P., 1983, Reputation and product quality, Bell Journal of Economics 2, 508-516.

Schneider, C.W., J. Manko and R. Kant, 1983. Going public: Practice, procedure, and consequences (Packard Press, Philadelphia, PA).

Smith, C.W., 1977, Alternative methods for raising capital: Rights versus underwritten agreements, Journal of Financial Economics 5, 273-307.

Standard and Poor's, 1977-82, Daily stock price record for over-the-counter stocks (Standard and Poor's Corporation, New York).

Telser, L.G., 1980, A theory of self-enforcing agreements, Journal of Business 53, 27-44.

Titman, S. and B. Trueman, 1985, Information quality and the valuation of new issues, Unpublished working paper (University of California, Los Angeles, CA). 